\title{
The long-term outcomes of radiosurgery for arteriovenous malformations in pediatric and adolescent populations
}

\author{
Shunya Hanakita, MD, ${ }^{1}$ Tomoyuki Koga, MD, PhD, ${ }^{1}$ Masahiro Shin, MD, PhD, ${ }^{1}$ \\ Hiroshi Igaki, MD, $\mathrm{PhD},{ }^{2}$ and Nobuhito Saito, MD, $\mathrm{PhD}^{1}$ \\ Departments of ${ }^{1}$ Neurosurgery and ${ }^{2}$ Radiology, The University of Tokyo Hospital, Tokyo, Japan
}

OBJECT Although stereotactic radiosurgery (SRS) has been accepted as a therapeutic option for arteriovenous malformations (AVMs) in children and adolescents, substantial data are still lacking regarding the outcomes of SRS for AVMs in this age group, especially long-term complications. This study aimed to clarify the long-term outcomes of SRS for the treatment of AVM in pediatric patients aged $\leq 18$ years.

METHODS Outcomes of 116 patients who were aged 4-18 years when they underwent SRS between 1990 and 2009 at the study institute were analyzed retrospectively.

RESULTS The median follow-up period after SRS was 100 months, with 6 patients followed up for more than 20 years. Actuarial obliteration rates at 3 and 5 years after SRS were $68 \%$ and $88 \%$, respectively. Five hemorrhages occurred in 851 patient-years of follow-up. The annual bleeding rate after SRS before obliteration was calculated as $1.3 \%$, which decreased to $0.2 \%$ after obliteration. Shorter maximum nidus diameter $(p=0.02)$ and higher margin dose $(p=0.03)$ were associated with a higher obliteration rate. Ten patients experienced adverse events after SRS. Of them, 4 patients presented with delayed complications years after SRS (range 9-20 years after SRS).

CONCLUSIONS SRS can reduce the risk of hemorrhage in pediatric and adolescent AVMs, with an acceptable risk of complications in the long term. However, adverse events such as expanding hematoma and radiation necrosis that can occur after substantial follow-up should be taken into account at the time that treatment decisions are made and informed consent is obtained.

http://thejns.org/doi/abs/10.3171/2015.1.PEDS14407

KEY WORDS arteriovenous malformation; children; Gamma Knife surgery; stereotactic radiosurgery

$C_{\text {in }}$ EREBRAL arteriovenous malformation (AVM) is one of the most frequent causes of cerebral hemorrhage in younger populations. ${ }^{29}$ Compared with AVMs in adults, AVMs in children and adolescents tend to more frequently show a hemorrhagic onset, $, 2,4$, which often necessitates therapeutic intervention. The goal of treatment for AVM is to eliminate the risk of further hemorrhage that could be fatal or impose long-lasting, severe neurological deficits. Because early elimination of the menace of life-threatening hemorrhage is one of the first priorities in resection, the procedure is often regarded as the first-choice treatment modality. ${ }^{12,13,32}$ On the other hand, radiosurgery offers an alternative for cases with a small residual nidus on angiography or with surgically intracta-

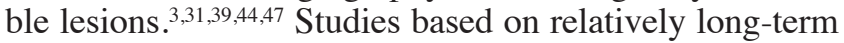

follow-up and observation after stereotactic radiosurgery (SRS) for patients in this age group have revealed the possibility of adverse events such as posttreatment hemorrhages, radiation necrosis, expanding hematomas, and radiation-induced malignant neoplasms. ${ }^{47,48}$ However, because of the rarity of pediatric patients with AVMs and the relatively short period after introduction of this treatment method, substantial long-term follow-up data are still lacking. We have previously reported early results of SRS for young patients with AVMs treated at our institute ${ }^{37}$ and concluded that radiosurgery offers a good treatment alternative to microsurgical resection. However, the follow-up period in that report was quite limited, considering the life expectancy of those patients. Therefore, in this series, we analyzed the data obtained through longer follow-up of a

ABBREVIATIONS AVM = arteriovenous malformation; DTT = diffusion tensor tractography; SRS = stereotactic radiosurgery.

SUBMITTED August 1, 2014. ACCEPTED January 12, 2015.

INCLUDE WHEN CITING Published online May 8, 2015; DOI: 10.3171/2015.1.PEDS14407.

DISCLOSURE The authors report no conflict of interest concerning the materials or methods used in this study or the findings specified in this paper. 
larger number of patients and evaluated the validity of this therapeutic modality for patients of this age group.

\section{Methods}

\section{Patients and Clinical Materials}

A retrospective database search was carried out. Between January 1991 and October 2009, a total of 116 patients (52 boys, 64 girls) $\leq 18$ years old with an intracranial AVM were treated by single-stage SRS using Leksell Gamma Knife at our institute. Two patients who underwent volume-staged SRS for excessive large AVM were excluded from this analysis. The review board of our institute approved the study protocol. In all patients, the diagnosis of AVM was confirmed with cerebral angiography in combination with CT or MRI. Forty-seven patients (41\%) had initially been treated with other modalities (resection in 20 , extraventricular drainage in 10 , endovascular treatment in 13 , and resection with endovascular treatment in 4) and were referred to our hospital to receive SRS for residual nidi. Of 34 patients who received any kind of surgery including extraventricular drainage, 32 patients received these treatments as an urgent operation for hemorrhagic presentation. Two patients who initially presented with nonhemorrhagic symptoms underwent resection as a first treatment. Twenty-one patients underwent endovascular treatment in combination with SRS. Among them, 16 patients presented with hemorrhage, of whom 4 patients received surgery as well. The other 5 patients presented with nonhemorrhagic symptoms. Embolization for the AVM was used for AVM-related aneurysms and high-flow shunt prior to SRS or resection. Since it has been shown that preceding endovascular treatment lowered the obliteration rate,, 34 we principally avoid endovascular treatment prior to SRS except for the cases accompanied by AVM-related aneurysms. All 3 patients who received endovascular treatment in the 2000s were treated at affiliate hospitals for initial hemorrhages. The endovascular treatments were occasionally divided into multiple stages: 10 patients were treated in a 1-stage procedure, 5 patients in a 2 -stage procedure, and 7 patients received $\geq 3$ sessions. The median time between last embolization and SRS was 3 months (range 1-36 months). The embolization materials used were $N$-butyl cyanoacrylate, silk suture, polyvinyl alcohol particles, and ethylene vinyl copolymer, which were available at each period.

Regarding decisions about treatment strategy, especially for hemorrhagic onset cases, we fully explained to patients and their parents that microsurgery was the most rational treatment for lower Spetzler-Martin grade (Grade I or II) lesions, as we previously reported. ${ }^{13}$ However, some patients and their families declined the resection option and were referred to our department for SRS. The treatment strategy was fully discussed at a joint conference with neurosurgeons, endovascular surgeons, and radiation oncologists. The radiosurgery-based grading score (AVM score) proposed by Pollock and Flickinger was used to evaluate patient outcomes. ${ }^{45}$ This score was calculated according to the following equation: $\mathrm{AVM}$ score $=0.1 \times$ $\left(\mathrm{AVM}\right.$ volume in $\left.\mathrm{cm}^{3}\right)+0.02 \times$ (patient age in years) +0.5 $\times$ (location: hemispheric/corpus callosum/cerebellar $=0$; basal ganglia/thalamus/brainstem $=1$ ).
Characteristics and clinical features of patients are summarized in Table 1. Median age at the time of SRS was 14 years (range 4-18 years). Median duration of follow-up was 100 months (range 5-276 months) after SRS. One hundred nine patients (94\%) were followed up for more than 2 years. The numbers of patients who were followed up for longer than 10, 15, and 20 years were 33 $(28 \%), 12(10 \%)$, and $6(5 \%)$, respectively.

Among 28 patients whose lesions were diagnosed without hemorrhage, the initial symptoms leading to diagnosis were seizure in 14 , headache in 8 , and incidental findings in 6 . Hemorrhage onset was seen in 88 patients $(76 \%)$. These 88 patients experienced 99 hemorrhages before SRS. Between the time of diagnosis and SRS, excluding the first hemorrhage in the 88 patients who initially presented with hemorrhage, 11 hemorrhagic events were observed during 147 patient-years. Using the person-years method, the annual hemorrhage rate after initial presentation until SRS was $7.5 \%$. The annual hemorrhage rate based on all hemorrhagic events during the entire life-period was $6.3 \%$ in our series. At the time of SRS, 36 patients (31\%) showed neurological deficits caused by past hemorrhage, comprising the following: motor weakness in 20; aphasia in 9; sensory disturbance in 6; disturbance of consciousness in 3; cranial nerve symptoms in 3; visual field disturbance in 2; and cerebellar ataxia in 1.

The location of the AVM was the cerebral hemispheres in 73 (frontal lobe in 34, temporal lobe in 11, parietal lobe in 14 , and occipital lobe in 14), corpus callosum in 14 , thalamus in 12 , cerebellum in 7 , basal ganglia in 6 , and brainstem in 4 . Median nidus volume was $1.8 \mathrm{~cm}^{3}$ (range $0.01-21.5 \mathrm{~cm}^{3}$ ) and median AVM score was 0.64 (range $0.18-2.47)$. For the Spetzler-Martin classification, ${ }^{40} 15$ were Grade I, 41 were Grade II, 44 were Grade III, 12 were Grade IV, and 4 were Grade VI. No patients harbored Grade V lesions in this series.

\section{Radiosurgical Treatment}

After the Leksell stereotactic frame was fixed on the patients' head, stereotactic imaging was performed to obtain precise information on the shape, volume, and 3D coordinates of the nidi. Treatment planning was based on angiography until February 1992. Thereafter, combination CT with contrast enhancement or MRI of Gd-enhanced time-of-flight sequences together with angiography became available. Treatment planning was jointly performed by a neurosurgeon and radiation oncologist using commercially available software. The first-generation treatment-planning software (KULA; Elekta AB), with which prescribed dose planning was manually superimposed on 2D radiographic images, was used until September 1998. Advanced planning software (Gamma Plan; Elekta AB), which enabled the display of multiple radiographic images superimposed with 3D dose distribution, was installed thereafter. The Leksell Gamma Knife, model B, was used before September 2006. The model, with robotized automatic positioning system (Gamma Knife 4C), has been in use since October 2006. In principle, the ideal dose applied to the margin of each AVM nidus was 20-25 Gy, with the use of $50 \%$ isodose lines. In our early experience, margin doses of 20-25 Gy were often used for small le- 
TABLE 1. Clinical characteristics and radiosurgical dosimetry for 116 children $\leq 18$ years old with AVM

\begin{tabular}{|c|c|}
\hline Characteristics & Value \\
\hline No. of patients in analysis & 116 \\
\hline Male/female ratio & $52: 64$ \\
\hline Median age at SRS, yrs (range) & $14(4-18)$ \\
\hline $4-10$ & 27 \\
\hline $11-15$ & 44 \\
\hline $15-18$ & 45 \\
\hline \multicolumn{2}{|l|}{ Initial clinical presentation (\%) } \\
\hline Headache & $8(7)$ \\
\hline Seizure & $14(12)$ \\
\hline Hemorrhage & $88(76)$ \\
\hline Incidental & $6(5)$ \\
\hline \multicolumn{2}{|l|}{ Location of nidus } \\
\hline Frontal lobe & 34 \\
\hline Temporal lobe & 11 \\
\hline Parietal lobe & 14 \\
\hline Occipital lobe & 14 \\
\hline Corpus callosum & 14 \\
\hline Thalamus & 12 \\
\hline Basal ganglia & 6 \\
\hline Cerebellum & 7 \\
\hline Brainstem & 4 \\
\hline \multicolumn{2}{|l|}{ Spetzler-Martin grade (\%) } \\
\hline I & $15(13)$ \\
\hline II & $41(35)$ \\
\hline III & $44(38)$ \\
\hline IV & $12(10)$ \\
\hline VI & $4(3)$ \\
\hline Annual hemorrhage rate before SRS (\%) & 7.5 \\
\hline Median nidus volume, $\mathrm{cm}^{3}$ (IQR) & $1.8(0.01-21.5)$ \\
\hline Median margin dose, Gy (range) & $20(12.5-25)$ \\
\hline Median maximum dose, Gy (range) & $40(25-60)$ \\
\hline Median AVM score (range) & $0.64(0.18-2.47)$ \\
\hline Median follow-up period, mos (range) & $100(5-276)$ \\
\hline
\end{tabular}

$I Q R=$ interquartile range.

sions; however, in accordance with a dose-response analysis that indicated 20 Gy was sufficient for AVM treatment, ${ }^{6}$ we prescribed 20 Gy or less thereafter. With lesions of larger volume, we tried to reduce the margin dose to no less than $16 \mathrm{~Gy}$, the suggested dose that can obliterate $70 \%$ of AVM in a dose-response analysis, ${ }^{6}$ while keeping the volume receiving 12 Gy smaller than roughly $20-25 \mathrm{~cm}^{3}$, which is considered a safe limit. ${ }^{5}$ Thus, from our experience, we regarded the upper limit of volume that could be treated in single-stage SRS as approximately $20 \mathrm{~cm}^{3} .^{10}$ Excessively larger lesions were not as suitable for singlestage SRS. In this series, we excluded the 2 patients who received volume-staged SRS during the study period. For lesions adjacent to critical organs, such as the optic nerve or brainstem, the margin dose was occasionally reduced. In practice, the maximum dose received by the optic nerve was restricted to less than $8 \mathrm{~Gy}$. We also treated lesions in the brainstem with at least 18 Gy to avoid posttreatment hemorrhage, as we previously reported, ${ }^{21}$ while the radiation tolerance limit of brainstem remained unclear. ${ }^{35}$ To avoid neurological deterioration, we began to integrate diffusion tensor tractography (DTT) into treatment planning, as previously reported.$^{17}$ Eleven patients have undergone this new modality since 2004: the pyramidal tract in 9 and the optic radiation in 2 (Fig. 1). Based on previous analyses, the tolerance dose of each fiber was set at $20 \mathrm{~Gy}$ for the pyramidal tract and 8 Gy for the optic radiation, ${ }^{26,27}$ and the treatment plan was modified so that the maximum doses received by these tracts did not exceed these dose levels. For exceptive cases, in the early experience at our institute, to avoid the risk of radiation injury, 1 patient with brainstem AVM underwent SRS with a margin dose of 12.5 Gy and another patient with a relatively large nidus in the frontal lobe was treated with a margin dose of $15 \mathrm{~Gy}$. Most patients received a margin dose of $\geq 20 \mathrm{~Gy}$. Median maximum dose was 40 Gy (range 25-60 Gy), and median margin dose was 20 Gy (range 12.5-25 Gy).

\section{Follow-Up Evaluation and Statistical Analysis}

After SRS, follow-up clinical examinations were performed at our hospital or by referring physicians. Patients underwent MRI or CT every 6 months. When nidus obliteration was strongly suggested from the results of these imaging modalities, angiography was performed. To screen for events such as the recurrence of lesions, de novo AVM, cyst formation, and expanding hematoma, annual MRI check-ups were performed even after nidus obliteration was achieved. The actuarial obliteration rate of the nidus was calculated using the Kaplan-Meier test. Factors potentially associated with higher obliteration were evaluated by Cox proportional hazard modeling for univariate and multivariate analyses. Factors related with adverse events were analyzed with logistic regression modeling for univariate and multivariate analyses. Comparisons of patients' characteristics between the 2 groups who underwent SRS with or without other preceding modalities were evaluated by 2 -sample t-test. All statistical analyses were performed using JMP 10 software (SAS Institute).

\section{Results}

\section{Obliteration Rate}

In this series, nidus obliteration confirmed by angiography $(n=82)$ or MRI $(n=6)$ was achieved in 88 patients after initial SRS. Median duration between obliteration and initial treatment was 24 months (range 8-65 months). At the time of this analysis, further angiographic evaluations were scheduled for 3 of the 6 MRI-confirmed patients; the other 3 patients declined further angiographic investigation. Actuarial obliteration rates at 2,3, and 5 years after initial SRS were 58\%,68\%, and 88\%, respectively. Among them, 71 patients $(81 \%)$ achieved nidus obliteration within 3 years after initial SRS. In other 17 patients, nidus obliteration was confirmed between 3 and 5 years after initial SRS. One patient who had initially showed hemorrhagic presentation underwent resection of the residual nidus 40 months after SRS because a residual nidus was obviously 

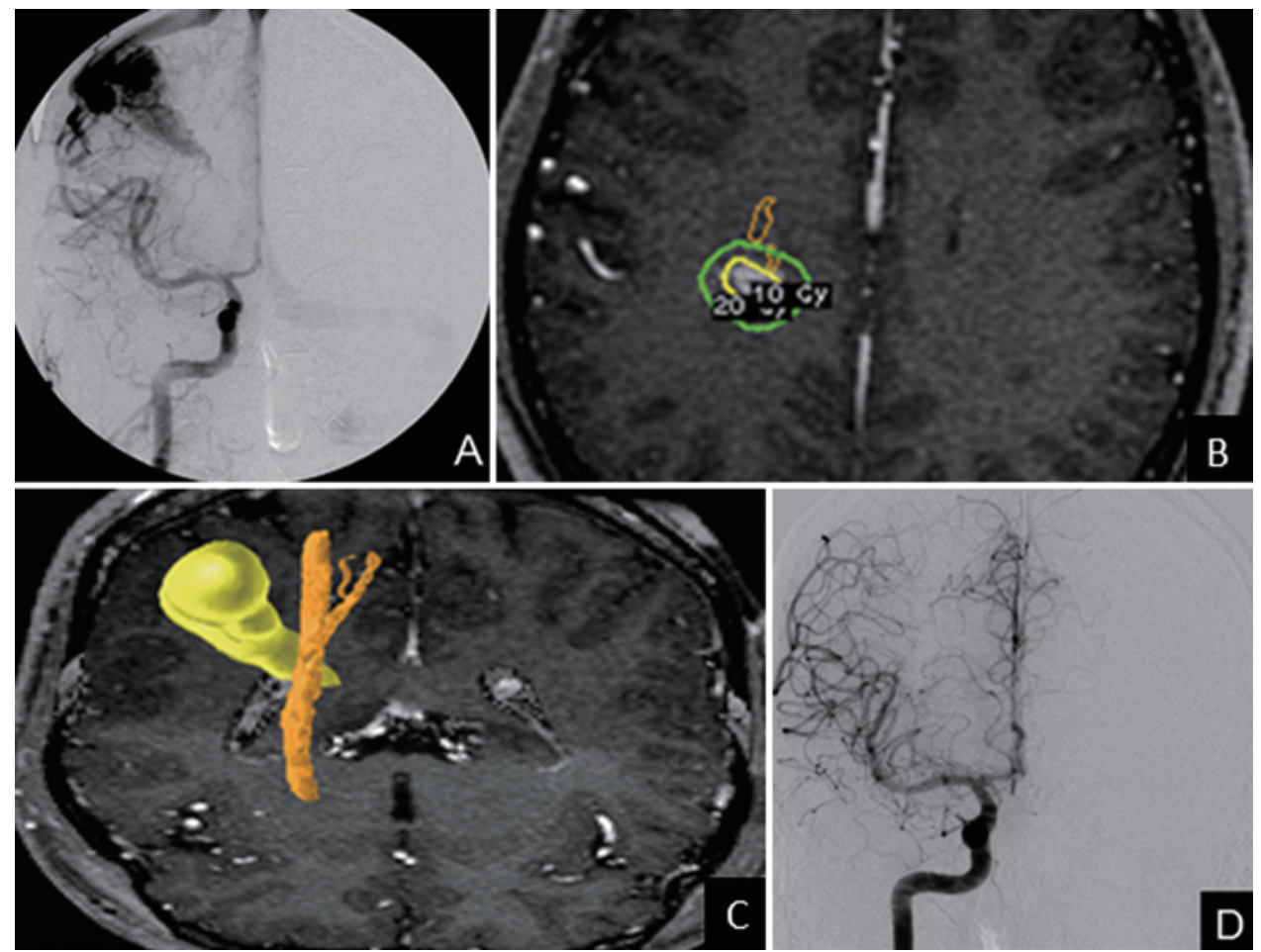

FIG. 1. Studies obtained in an 18-year-old boy. A: Angiogram showing an AVM in the right frontal lobe. B: Treatment plan based on MRI. The orange line shows the pyramidal tract adjacent to the nidus (yellow line). Treatment planning was performed so that the dose received by the pyramidal tract did not exceed the maximum dose of $20 \mathrm{~Gy}$. C: 3D structure of a nidus and pyramidal tract (yellow shows the nidus; orange, the pyramidal tract). D: Angiographic obliteration was achieved 4 years after SRS, and the patient suffered no deficits. Figure is available in color online only.

detected on follow-up angiography at 3 years. Eleven patients underwent a second SRS for residual nidus after sufficient follow-up. Nine of these 11 patients achieved nidus obliteration, confirmed on angiography. The remaining 2 patients were kept under observation and in these patients reduction of the nidi was demonstrated on MRI. Four patients had residual nidi after ample follow-up (> 5 years), but they declined further intervention and were observed conservatively. In total, 97 patients (84\%) achieved nidus obliteration after single or repeated SRS in our series. In the univariate analysis, factors associated with higher nidus obliteration were shorter maximum nidus diameter $(\mathrm{p}$ $=0.02)$ and higher margin dose $(\mathrm{p}=0.03)$ (Table 2). There was no significant factor associated with higher obliteration rate in multivariate analyses (Table 3 ).

\section{Complications and Hemorrhagic Events}

Five latency hemorrhages were found in 5 patients $(4.3 \%)$ at a median of 59 months after treatment (range 30-151 months). Five hemorrhages were observed in 815 patient-years; thus, the annual hemorrhage risk in the follow-up period was calculated as $0.6 \%$. Of these, 1 hemorrhagic event was observed even after obliteration (angiographic obliteration was confirmed at 48 months and hemorrhage presented at 75 months after SRS). The annual bleeding rate in the period between treatment and obliteration was calculated as 1.3\% (4 hemorrhages in 299 patient-years) and $0.2 \%$ after obliteration (1 hemorrhage in 516 patient-years). There was no factor associated with hemorrhage after SRS in both univariate and multivariate analyses (Tables 2 and 3).

Radiation-induced adverse events were observed within 2 years of SRS (median 9 months, range 3-16 months) in $6(5 \%)$ of 116 patients. Two patients showed transient dysesthesia 2 months and 3 months after SRS, which gradually improved within 6 months. One patient had a worsened existing symptom (motor weakness) 3 months after SRS, which improved within 3 months. Four patients showed new development of permanent events, with visual field deficit in 2 patients, dysesthesia in 1 patient, and motor weakness in 1 patient. In the univariate analysis, there was no significant factor associated with adverse events (Table 2). In multivariate analyses, the one factor associated with adverse events was higher margin dose $(\mathrm{p}=0.04)($ Table 3$)$.

In total, none of the patients presented with radiationinduced neoplasms during the follow-up period in this series. Four patients had late-onset complications that occurred more than 2 years after SRS (Table 4). One patient presented with cyst formation, and she remained asymptomatic and was observed conservatively (Case 1). Two patients developed chronic expanding hematomas that required resection (Cases 2 and 3). One patient (Case 4) presented with radiation-induced edema 20 years after SRS. This patient underwent resection of the abnormally enhanced region because she presented with mild motor weakness due to increasing intracranial pressure that 
TABLE 2. Univariate analysis for higher obliteration rate and adverse events

\begin{tabular}{|c|c|c|c|c|c|c|}
\hline \multirow[b]{2}{*}{ Factor } & \multicolumn{2}{|c|}{ Higher Obliteration Rate } & \multicolumn{2}{|c|}{ Adverse Events } & \multicolumn{2}{|c|}{ Hemorrhage After SRS } \\
\hline & $\mathrm{HR}(95 \% \mathrm{Cl})$ & $p$ Value & $\operatorname{HR}(95 \% \mathrm{Cl})$ & $p$ Value & $\operatorname{HR}(95 \% \mathrm{Cl})$ & $p$ Value \\
\hline Age & $1.00(0.95-1.06)$ & 0.95 & $0.97(0.79-1.20)$ & 0.53 & $1.09(0.84-1.55)$ & 0.38 \\
\hline Male/female ratio & $1.16(0.76-1.80)$ & 0.50 & $0.92(0.17-4.35)$ & 0.63 & $0.40(0.02-2.74)$ & 0.37 \\
\hline History of hemorrhage & $1.13(0.71-1.87)$ & 0.62 & $0.21(0.04-1.02)$ & 0.06 & $0.88(0.05-5.97)$ & 0.91 \\
\hline Increasing volume & $0.95(0.90-1.00)$ & 0.07 & $1.11(0.95-1.27)$ & 0.66 & $0.83(0.50-1.12$ & 0.29 \\
\hline Increasing maximum diameter & $0.97(0.95-0.99)$ & $0.02^{*}$ & $1.05(0.98-1.13)$ & 0.39 & $0.98(0.87-1.06)$ & 0.62 \\
\hline Deep venous drainage & $1.15(0.75-1.77)$ & 0.53 & $0.94(0.20-4.98)$ & 0.45 & $0.85(0.14-6.47)$ & 0.86 \\
\hline Eloquent area & $1.18(0.77-1.86)$ & 0.45 & $3.76(0.61-72.3)$ & 0.20 & $0.67(0.11-5.22)$ & 0.67 \\
\hline \multicolumn{7}{|l|}{ Previous treatment } \\
\hline Endovascular treatment & $1.19(0.51-1.45)$ & 0.52 & NT & - & NT & - \\
\hline Resection & $1.37(0.81-2.22)$ & 0.23 & NT & - & NT & - \\
\hline \multicolumn{7}{|l|}{ Radiosurgical dosimetry } \\
\hline Higher margin dose & $1.10(1.01-1.20)$ & $0.03^{*}$ & $1.09(0.78-1.48)$ & 0.60 & $1.13(0.79-1.59)$ & 0.48 \\
\hline Increasing AVM score & $0.64(0.38-1.02)$ & 0.06 & $2.91(0.69-10.6)$ & 0.14 & $0.11(0.01-1.78)$ & 0.14 \\
\hline Treated solely by angiography & $1.16(0.67-1.90)$ & 0.58 & $0.98(0.04-14.0)$ & 0.99 & $0.63(0.03-4.23)$ & 0.67 \\
\hline $\begin{array}{l}\text { Use of new-generation treatment- } \\
\text { planning software }\end{array}$ & $1.46(0.60-3.53)$ & 0.40 & $2.46(0.79-7.78)$ & 0.12 & $1.08(0.05-7.75)$ & 0.95 \\
\hline
\end{tabular}

proved refractory to medication and hyperbaric oxygen therapy. After surgery, symptoms completely resolved within 3 months (Fig. 2). Histopathological examination of the resected specimens showed hyalinized tissue and thin-wall vessel structures with endothelial cells. Collections of hemosiderin-laden macrophages were detected around vascular structures (Fig. 3). The disruption of the vascular structure could have induced such abnormal enhancement. No patient had AVM recurrence in this series; however, 1 patient whose occipital AVM was initially treated with SRS presented with a de novo temporal lobe AVM 13 years after initial SRS. This lesion was successfully treated with SRS, and angiographic obliteration was achieved 3 years after the second SRS.

\section{SRS Treatment With or Without Preceding Treatment}

As for multidisciplinary treatment, our series included 47 patients $(41 \%)$ who had treatment prior to SRS. We divided patients into 2 groups: those who underwent SRS

TABLE 3. Multivariate analyses for higher obliteration rate and adverse events

\begin{tabular}{|c|c|c|c|c|c|c|}
\hline \multirow[b]{2}{*}{ Factor } & \multicolumn{2}{|c|}{ Higher Obliteration Rate } & \multicolumn{2}{|c|}{ Adverse Events } & \multicolumn{2}{|c|}{ Hemorrhage After SRS } \\
\hline & $\mathrm{HR}(95 \% \mathrm{Cl})$ & p Value & $\mathrm{HR}(95 \% \mathrm{Cl})$ & p Value & $\mathrm{HR}(95 \% \mathrm{Cl})$ & $p$ Value \\
\hline Age & $0.97(0.90-1.04)$ & 0.38 & $0.82(0.59-1.10)$ & 0.20 & $1.09(0.81-1.60)$ & 0.59 \\
\hline Male/female ratio & $1.43(0.88-2.33)$ & 0.14 & $0.41(0.05-2.49)$ & 0.35 & $0.38(0.02-2.86)$ & 0.37 \\
\hline History of hemorrhage & $0.90(0.47-1.81)$ & 0.77 & $0.21(0.02-1.71)$ & 0.06 & $0.80(0.07-18.7)$ & 0.86 \\
\hline Increasing volume & $1.03(0.93-1.14)$ & 0.52 & $1.03(0.78-1.32)$ & 0.79 & $0.65(0.25-1.18)$ & 0.21 \\
\hline Increasing maximum diameter & $0.13(0.93-1.00)$ & 0.10 & $1.08(0.95-1.21)$ & 0.20 & $1.07(0.88-1.30)$ & 0.46 \\
\hline Deep venous drainage & $1.21(0.72-2.04)$ & 0.47 & $2.38(0.05-2.49)$ & 0.41 & $0.95(0.13-2.86)$ & 0.96 \\
\hline Eloquent area & $1.12(0.69-1.86)$ & 0.64 & $3.95(0.56-85.8)$ & 0.24 & $0.63(0.08-5.77)$ & 0.66 \\
\hline \multicolumn{7}{|l|}{ Previous treatment } \\
\hline Endovascular treatment & $1.17(0.63-2.08)$ & 0.61 & NT & - & NT & - \\
\hline Resection & $1.12(0.62-1.96)$ & 0.69 & NT & - & NT & - \\
\hline \multicolumn{7}{|l|}{ Radiosurgical dosimetry } \\
\hline Higher margin dose & $1.06(0.96-1.17)$ & 0.23 & $1.76(1.02-3.47)$ & $0.04^{*}$ & $1.07(0.70-1.73)$ & 0.75 \\
\hline Increasing AVM score & NT & - & NT & - & NT & - \\
\hline Treated solely by angiography & $0.78(0.72-2.04)$ & 0.42 & $0.96(0.04-13.5)$ & 0.98 & $0.72(0.03-6.86)$ & 0.78 \\
\hline $\begin{array}{l}\text { Use of new-generation treat- } \\
\text { ment-planning software }\end{array}$ & $0.92(0.01-31.4)$ & 0.96 & $2.71(0.10-73.3)$ & 0.53 & $2.04(0.07-32.6)$ & 0.63 \\
\hline
\end{tabular}

* Statistically significant values $(p<0.05)$. 
TABLE 4. Summary of patients who developed delayed complications that occurred years later after SRS

\begin{tabular}{cccccccccccc}
\hline $\begin{array}{c}\text { Case } \\
\text { No. }\end{array}$ & $\begin{array}{c}\text { Age }(\mathrm{yrs}), \\
\text { Sex }\end{array}$ & $\begin{array}{c}\text { Initial } \\
\text { Presentation }\end{array}$ & $\begin{array}{c}\text { Nolume } \\
\left(\mathrm{cm}^{3}\right)\end{array}$ & $\begin{array}{c}\text { Margin/Max } \\
\text { Dose }(\mathrm{Gy})\end{array}$ & $\begin{array}{c}\text { Diameter } \\
(\mathrm{mm})\end{array}$ & Location & $\begin{array}{c}\text { Venous } \\
\text { Drainage }\end{array}$ & $\begin{array}{c}\text { S-M } \\
\text { Grade }\end{array}$ & $\begin{array}{c}\text { Sumptoms } \\
\text { (yrs) }\end{array}$ & $\begin{array}{c}\text { Clinical } \\
\text { Outcome* }\end{array}$ \\
\hline 1 & $18, \mathrm{~F}$ & Hemorrhage & 5.1 & $20 / 40$ & 25 & Basal ganglia & Deep & IV & 16 & Asymptomatic & 0 \\
\hline 2 & $18, \mathrm{~F}$ & Seizure & 1.8 & $25 / 50$ & 19 & Occipital lobe & Superficial & II & 9 & Headache & 1 \\
\hline 3 & $10, \mathrm{M}$ & Hemorrhage & 8.6 & $20 / 40$ & 33 & Occipital lobe & Deep & IV & 15 & Headache & 0 \\
\hline 4 & $12, \mathrm{~F}$ & Seizure & 5.4 & $20 / 40$ & 28 & Frontal lobe & Superficial & II & 20 & $\begin{array}{c}\text { Motor weakness, } \\
\text { headache }\end{array}$ & 0 \\
\hline
\end{tabular}

S-M = Spetzler-Martin.

* Outcome is presented as a modified Rankin Scale score.

as a primary treatment (SRS-only group) and those who received combination treatment, surgery, and/or endovascular treatment with SRS (combination group). The characteristics of each group are summarized in Table 5. The rate of patients who presented with hemorrhage was significantly higher in the combination group $(\mathrm{p}=0.01)$, and the rate of deep-seated lesions, such as thalamic lesions, was significantly higher in the SRS-only group $(\mathrm{p}=0.02)$. The obliteration rate and adverse events were not significantly different between the 2 groups (Table 5).

\section{Outcomes of Integration of DTT}

Regarding the integration of DTT into radiosurgical planning, DTT was used for only 11 patients: 9 for the pyramidal tract and 2 for the optic radiation. No adverse events were observed in these 11 patients. Retrospectively, 8 patients who were treated before the introduction of DTT harbored lesions in the deep frontal lobe, basal ganglia, or thalamus, which were considered close to the pyramidal tract. Comparison of the outcomes of these 8 patients and the 9 patients for whom pyramidal tract DTT was used showed no significant difference in obliteration rate $(\mathrm{p}=$ $0.60)$ or adverse events $(\mathrm{p}=0.89)$.

\section{Discussion}

Controversy exists regarding therapeutic intervention for pediatric AVM. According to the recent literature comparing the long-term hemorrhage risk between pediatric and adult AVM patients, ${ }^{8}$ AVMs in childhood were more
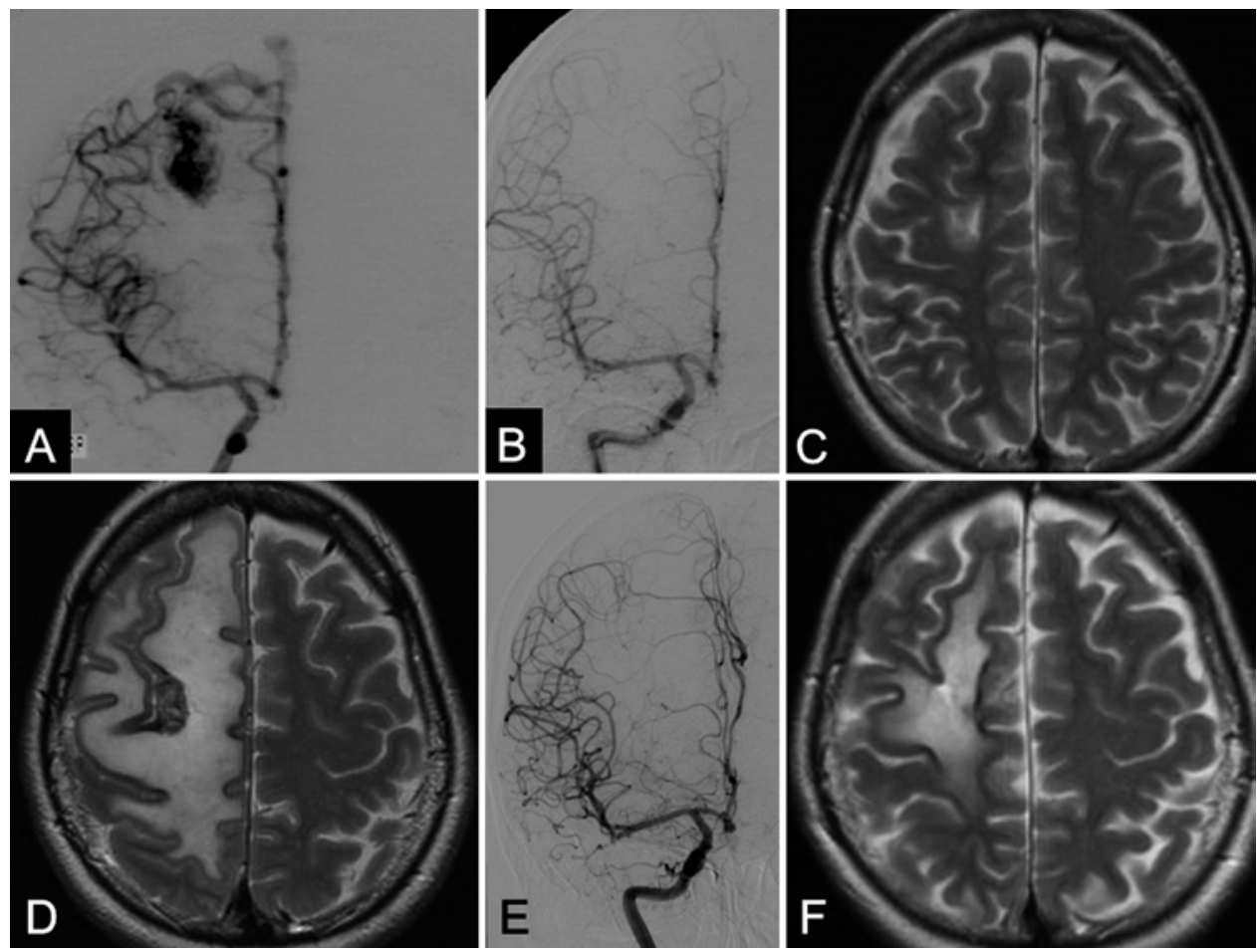

FIG. 2. Studies obtained in a 12-year-old girl. A: Angiogram showing an AVM in the right frontal lobe that was treated by SRS with a margin dose of $20 \mathrm{~Gy}$. B: Two years after SRS, complete nidus obliteration was confirmed on angiography. C: Obliterated nidus on T2-weighted imaging remained unchanged during the follow-up period (imaging at 14 years after SRS). D and E: Twenty years after SRS, this patient presented with paresis and regions of hyperintensity on T2-weighted imaging detected around the obliterated nidus. Nidus obliteration was continuously observed on angiography. F: Hyperintense regions on T2-weighted imaging decreased within 3 months after surgical removal of the abnormal enhanced lesion. Symptoms completely resolved. 


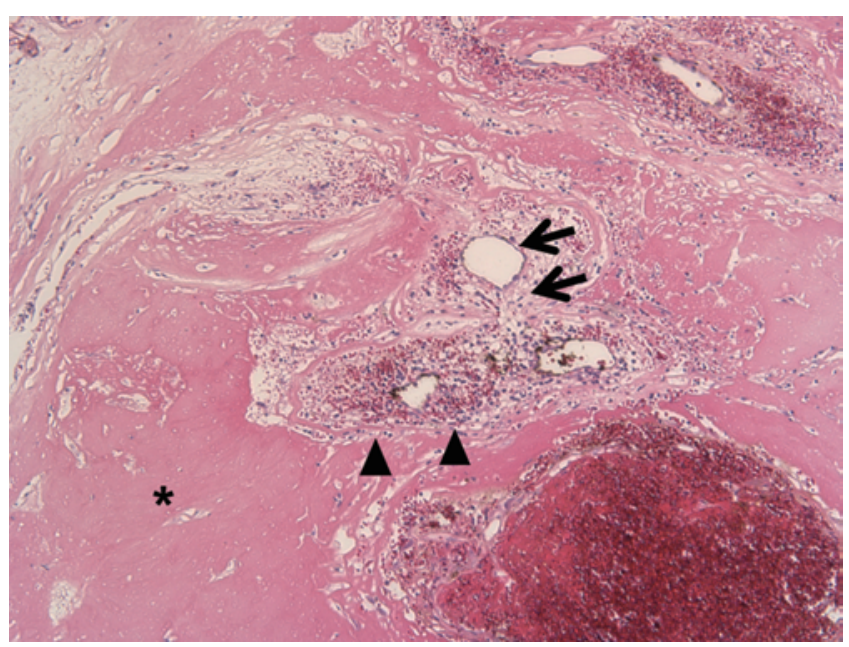

FIG. 3. Histopathological examination of the resected specimen shows hyalinized tissue (asterisk) and thin-wall vessel structures with endothelial cells (arrows). Collections of hemosiderin-laden macrophages were detected around vascular structures (arrowheads). There was no evidence of malignancy. $H \& E$, original magnification $\times 40$. Figure is available in color online only.

likely to present initially with hemorrhage, but the risk of subsequent hemorrhage was lower than that of AVMs in adults. Also, the recent randomized study of unruptured AVMs (ARUBA [A Randomized Trial of Unruptured Brain Arteriovenous Malformations]) disclosed that medical management alone was superior to interventional therapy for unruptured AVMs in adults for the prevention of death or stroke in the short-term period. ${ }^{30}$ Those results suggest that even for ruptured AVMs, children may be better protected than adults and, therefore, the decision of interventional treatment must be made very carefully, considering the long-term outcomes of each therapeutic option, the success rates in preventing further hemorrhagic events, and the associated risk of complications. On the other hand, children with AVMs and their parents have to live with the "small but non-negligible" menace of a possible hemorrhagic event. Thus, when the risks of complication are estimated to be lower than the risks associated with conservative observation, therapeutic intervention will be reasonably recommended.

In past reports, several authors indicated that AVMs with a hemorrhagic onset have higher risk of subsequent hemorrhage, , 4,16,42,46 and resection can be recommended as a first-line treatment. Microsurgical resection has a clear benefit in immediately eliminating the hemorrhage risk, but the outcomes of resection largely depend on size and location of the nidus, eloquence of the surrounding brain, and skill of each neurosurgeon. Even for AVMs classified as Spetzler-Martin Grade I or II, the risks of surgical complications vary from $0 \%$ to $20 \% .^{11,13,24}$ While some of the neurological deficits gradually improve over time, it is very difficult to assess if we can legitimately offer those "immediate and single-phase risks" for children with plateau neurological states.

Taking this into consideration, SRS, in general, can offer a reasonable therapeutic option for the pediatric AVM with a small nidus. According to previous reports, pediatric AVM was found to show earlier obliteration than that of adult AVM. ${ }^{31}$ The therapeutic outcomes were relatively homogeneous among the reports, and the associated neurological deficits were minimal (Table 6), ${ }^{3,15,31,33,39,44} \mathrm{Re}-$ garding multidisciplinary treatment, the one reason that there was no difference between the SRS-only group and the combined treatment group in terms of treatment outcomes can be attributable to this study being a retrospective analysis looking at whether treatment options other than SRS were applied or not, depending on careful consideration of the patient situation, such as existence of hematoma, location of the lesions, accompanying aneurysms, and high-flow shunts. Further, the limitations of this study include the lack of statistical power due to a small patient population.

In our series, 6 patients $(5 \%)$ had radiation-induced neurological deterioration within 2 years, 3 of whom harbored an AVM in the eloquent areas. They were treated in the early period of the study before introduction of sophisticated dose-planning software and DTT into treatment planning. ${ }^{26}$ Since 2004, we have integrated DTT into treatment planning to reduce the doses received by each tract for the purpose of eliminating adverse events

TABLE 5. Comparisons of the characteristics of the 2 groups with or without preradiosurgical treatment

\begin{tabular}{llll}
\hline \multicolumn{1}{c}{ Characteristic } & SRS Only & Combination & p Value \\
\hline No. of patients & 69 & 47 & 0.52 \\
\hline Mean patient age in yrs (range) & $13(6-18)$ & $13(4-18)$ & 0.57 \\
\hline Male (\%) & $29(42)$ & $23(47)$ & $0.01^{*}$ \\
\hline Hemorrhage before treatment (\%) & $46(68)$ & $42(87)$ & 0.42 \\
\hline Mean max nidus diameter in mm (range) & $22(3-44)$ & $23(8-68)$ & 0.47 \\
\hline Deep draining vein (\%) & $30(63)$ & $38(56)$ & 0.14 \\
\hline Eloquent area (\%) & $39(57)$ & $34(70)$ & $0.02^{*}$ \\
\hline Thalamus (\%) & $11(16)$ & $1(2)$ & 0.16 \\
\hline Mean treated volume in cm ${ }^{3}$ (range) & $4.1(0.01-21.5)$ & $3.0(0.13-10.4)$ & 0.57 \\
\hline Mean AVM score (range) & $0.74(0.19-2.47)$ & $0.70(0.24-1.19)$ & 0.08 \\
\hline Obliteration rate at 5 yrs (\%) & 85 & 92 & 0.20 \\
\hline Adverse events & 8 & 2 & \\
\hline
\end{tabular}

* Statistically significant values $(p<0.05)$. 
TABLE 6. Previously published results of Gamma Knife surgery for AVM in children

\begin{tabular}{|c|c|c|c|c|c|c|c|c|c|}
\hline \multirow[b]{2}{*}{ Authors \& Year } & \multirow[b]{2}{*}{$\begin{array}{l}\text { No. of } \\
\text { Pts }\end{array}$} & \multirow[b]{2}{*}{ Age } & \multirow{2}{*}{$\begin{array}{c}\text { Median } \\
\text { Margin Dose } \\
\text { (Gy) }\end{array}$} & \multirow{2}{*}{$\begin{array}{c}\text { Median } \\
\text { Follow-Up } \\
\text { (mos) }\end{array}$} & \multirow[b]{2}{*}{$\begin{array}{l}\text { Median Volume } \\
\qquad\left(\mathrm{cm}^{3}\right)\end{array}$} & \multicolumn{2}{|c|}{ Obliteration Rate (\%) } & \multirow[b]{2}{*}{$\begin{array}{c}\text { Adverse } \\
\text { Events (\%) }\end{array}$} & \multirow[b]{2}{*}{$\begin{array}{c}\text { ABR After } \\
\text { Treatment (\%) }\end{array}$} \\
\hline & & & & & & $\begin{array}{c}\text { After } \\
\text { 1st SRS }\end{array}$ & $\begin{array}{l}\text { Entire } \\
\text { Series }\end{array}$ & & \\
\hline Smyth et al., 2002 & 31 & $11(3-17)$ & 18 & $60(6-99)$ & $1.6(0.15-37.4)$ & 27 & 35 & 6 & 3.2 \\
\hline Nicolato et al., 2006 & 75 & $14(5-20)$ & 22 & $29(6-77)$ & $2.9(0.1-25.0)$ & 86 & 86 & 1.3 & 0.56 \\
\hline $\begin{array}{l}\text { Cohen-Gadol \& Pollock, } \\
\quad 2006\end{array}$ & 38 & $15(7-18)$ & 20 & $42(12-131)$ & $3.4(0.2-33)$ & 54 & 68 & 0 & NA \\
\hline Pan et al., 2008 & 100 & $12(2-18)$ & $18.5^{*}$ & $25(6-134)$ & $11.7(0.4-63)$ & 65 & 81 & 8 & 1.9 \\
\hline Yen et al., 2010 & 186 & $12(4-18)$ & $21.9^{*}$ & $80 *(6-222)$ & $3.2^{*}(0.1-24.0)$ & 58 & 59 & 3.2 & 2.6 \\
\hline Kano et al., $2012^{15}$ & 135 & $12(2-17)$ & 20 & $71(6-264)$ & $2.5(1-17.5)$ & 43 & 54 & 6 & 1.8 \\
\hline Tamura et al., 2012 & 22 & $9.5(4-14)$ & 22 & $47(29-92)$ & $1.2(0.1-6.7)$ & 77 & 77 & 9 & NA \\
\hline Present study & 116 & $14(4-18)$ & 20 & $100(5-276)$ & $1.8(0.01-22.5)$ & 76 & 84 & 5 & $1.3 / 0.2 \dagger$ \\
\hline
\end{tabular}

$\mathrm{ABR}=$ annual bleeding rate; $\mathrm{NA}=$ data not available; $\mathrm{Pts}=$ patients.

* Data represent mean values.

† Rate was $1.3 \%$ before obliteration and $0.2 \%$ after obliteration.

related to these white matter tracts. All patients, including adults, who were treated with SRS using the pyramidal tract DTT showed a significantly reduced motor complication rate compared with patients having lesions in similar locations who were treated before the availability of DTT integration. ${ }^{18}$ However, this influence was not apparent in this study cohort of pediatric patients, probably because of the small number of patients who were treated with integration of DTT. Although the devices and software for SRS treatment have changed throughout the study period, and these factors are known to affect outcomes in selected patients, ${ }^{18-20}$ treatment outcomes such as obliteration and adverse events in this cohort were not affected by these factors. Further accumulation of cases is needed to analyze the influence of these new technologies on patients in this age group.

The annual risk of hemorrhage, especially in the period after obliteration was achieved, was $0.2 \%$, which indicates that the "long-lasting and unclarified" risks associated with SRS may be comparable to the "small and nonnegligible" risks of the natural history of pediatric AVM itself. ${ }^{8}$ As for the patients treated with SRS, even when the residual nidus was observed 3-5 years after treatment, the risk of hemorrhagic events was significantly reduced, ${ }^{28}$ and both additional SRS and the resection could be safely performed., ${ }^{7,43}$ In our series, the latency hemorrhages from a residual nidus after 5 years were observed in 2 patients 60 months and 151 months after SRS. These cases suggest that it is very important to recommend the additional treatment within a proper timeframe, ideally before 5 years because it is very rare that an AVM nidus shows further response later than 5 years after SRS. ${ }^{31,38}$ SRS is a relatively new treatment modality, and recently we realized that angiographic obliteration of an AVM nidus is not the end point of the treatment. ${ }^{25,28,36}$ Furthermore, in this series, we found that radiation-induced adverse effects could occur more than 20 years after SRS. While the pathogenesis of radiation necrosis is not fully understood, radiation therapy could cause disruption of the blood-brain barrier, which was observed in all phases, from the acute phase to the delayed phase. Hyperlucency from endothe- lial damage seems to be the result of a similar mechanism of cyst formation and expanding hematoma, as previously reported. ${ }^{22}$ Corticosteroids and other kinds of medication and treatment were often used for these conditions, including vitamin E, pentoxifylline, and hyperbaric oxygen. However, the abnormal enhanced lesions were often refractory to treatment, and thus resection was considered. There have been only a few cases that presented with radiation necrosis in a proven pathological specimen over the past decades. Considering the effects of those late events while planning treatment for patients with long lives ahead of them is important, but our understanding of the longterm risks after radiosurgery, including radiation-induced neoplasm, post-SRS cyst, chronic expanding hematoma, and radiation necrosis, is still limited. Beyond the longterm adverse events related to SRS, such as cyst formation, chronic expanding hematoma, radiation necrosis, and radiation-induced neoplasms, the possibility of recurrence of the AVM or a de novo $\mathrm{AVM}^{1,23}$ should also be noted for pediatric patients. Even though the incidence of these adverse events or formation of new lesions is relatively low, these possibilities should be kept in mind and be extensively discussed with patients and families, and patients should be followed up carefully and appropriately managed should they occur.

\section{Conclusions}

This study assessed the efficacy and safety of SRS for AVMs in children $\leq 18$ years old, showing an obliteration rate of $88 \%$ at 5 years and an incidence of adverse events of 5\%. Longer-term follow-up data suggested that SRS is an effective treatment for small lesions, with relatively low risk of morbidity. Follow-up over decades is necessary because adverse events such as expanding hematoma and radiation necrosis can occur many years after treatment, as seen in our cases.

\section{References}

1. Bulsara KR, Alexander MJ, Villavicencio AT, Graffagnino 
C: De novo cerebral arteriovenous malformation: case report. Neurosurgery 50:1137-1141, 2002

2. Celli P, Ferrante L, Palma L, Cavedon G: Cerebral arteriovenous malformations in children. Clinical features and outcome of treatment in children and in adults. Surg Neurol 22:43-49, 1984

3. Cohen-Gadol AA, Pollock BE: Radiosurgery for arteriovenous malformations in children. J Neurosurg 104 (6 Suppl):388-391, 2006

4. da Costa L, Wallace MC, ter Brugge KG, O'Kelly C, Willinsky RA, Tymianski M: The natural history and predictive features of hemorrhage from brain arteriovenous malformations. Stroke 40:100-105, 2009

5. Flickinger JC, Kondziolka D, Maitz AH, Lunsford LD: An analysis of the dose-response for arteriovenous malformation radiosurgery and other factors affecting obliteration. Radiother Oncol 63:347-354, 2002

6. Flickinger JC, Pollock BE, Kondziolka D, Lunsford LD: A dose-response analysis of arteriovenous malformation obliteration after radiosurgery. Int J Radiat Oncol Biol Phys 36:873-879, 1996

7. Foote KD, Friedman WA, Ellis TL, Bova FJ, Buatti JM, Meeks SL: Salvage retreatment after failure of radiosurgery in patients with arteriovenous malformations. J Neurosurg 98:337-341, 2003

8. Fullerton HJ, Achrol AS, Johnston SC, McCulloch CE, Higashida RT, Lawton MT, et al: Long-term hemorrhage risk in children versus adults with brain arteriovenous malformations. Stroke 36:2099-2104, 2005

9. Graf CJ, Perret GE, Torner JC: Bleeding from cerebral arteriovenous malformations as part of their natural history. $\mathbf{J}$ Neurosurg 58:331-337, 1983

10. Hanakita S, Koga T, Shin M, Igaki H, Saito N: Application of single-stage stereotactic radiosurgery for cerebral arteriovenous malformations $>10 \mathrm{~cm} 3$. Stroke 45:3543-3548, 2014

11. Hartmann A, Stapf C, Hofmeister C, Mohr JP, Sciacca RR, Stein BM, et al: Determinants of neurological outcome after surgery for brain arteriovenous malformation. Stroke 31:2361-2364, 2000

12. Hashimoto N, Nozaki K, Takagi Y, Kikuta K, Mikuni N: Surgery of cerebral arteriovenous malformations. Neurosurgery 61 (1 Suppl):375-389, 2007

13. Heros RC, Korosue K, Diebold PM: Surgical excision of cerebral arteriovenous malformations: late results. Neurosurgery 26:570-578, 1990

14. Kano H, Kondziolka D, Flickinger JC, Yang HC, Flannery TJ, Awan NR, et al: Stereotactic radiosurgery for arteriovenous malformations, Part 3: outcome predictors and risks after repeat radiosurgery. J Neurosurg 116:21-32, 2012

15. Kano H, Kondziolka D, Flickinger JC, Yang HC, Flannery TJ, Awan NR, et al: Stereotactic radiosurgery for arteriovenous malformations, Part 2: management of pediatric patients. J Neurosurg Pediatr 9:1-10, 2012

16. Kim H, McCulloch CE, Johnston SC, Lawton MT, Sidney S, Young WL: Comparison of 2 approaches for determining the natural history risk of brain arteriovenous malformation rupture. Am J Epidemiol 171:1317-1322, 2010

17. Koga T, Maruyama K, Kamada K, Ota T, Shin M, Itoh D, et al: Outcomes of diffusion tensor tractography-integrated stereotactic radiosurgery. Int J Radiat Oncol Biol Phys 82:799-802, 2012

18. Koga T, Shin M, Maruyama K, Kamada K, Ota T, Itoh D, et al: Integration of corticospinal tractography reduces motor complications after radiosurgery. Int J Radiat Oncol Biol Phys 83:129-133, 2012

19. Koga T, Shin M, Maruyama K, Kurita H, Kawamoto S, Saito $\mathrm{N}$ : Contribution of technological progress, inter-operator difference and experience of operators in Gamma Knife radiosurgery for arteriovenous malformation. Acta Neurochir (Wien) 153:879-882, 2011
20. Koga T, Shin M, Maruyama K, Terahara A, Saito N: Longterm outcomes of stereotactic radiosurgery for arteriovenous malformations in the thalamus. Neurosurgery 67:398-403, 2010

21. Koga T, Shin M, Terahara A, Saito N: Outcomes of radiosurgery for brainstem arteriovenous malformations. Neurosurgery 69:45-52, 2011

22. Kurita H, Sasaki T, Kawamoto S, Taniguchi M, Kitanaka C, Nakaguchi H, et al: Chronic encapsulated expanding hematoma in association with gamma knife stereotactic radiosurgery for a cerebral arteriovenous malformation. Case report. J Neurosurg 84:874-878, 1996

23. Lang SS, Beslow LA, Bailey RL, Vossough A, Ekstrom J, Heuer GG, et al: Follow-up imaging to detect recurrence of surgically treated pediatric arteriovenous malformations. J Neurosurg Pediatr 9:497-504, 2012

24. Lawton MT, Kim H, McCulloch CE, Mikhak B, Young WL: A supplementary grading scale for selecting patients with brain arteriovenous malformations for surgery. Neurosurgery 66:702-713, 2010

25. Lindqvist M, Karlsson B, Guo WY, Kihlström L, Lippitz $\mathrm{B}$, Yamamoto M: Angiographic long-term follow-up data for arteriovenous malformations previously proven to be obliterated after gamma knife radiosurgery. Neurosurgery 46:803-810, 2000

26. Maruyama K, Kamada K, Shin M, Itoh D, Aoki S, Masutani $\mathrm{Y}$, et al: Integration of three-dimensional corticospinal tractography into treatment planning for gamma knife surgery. $\mathbf{J}$ Neurosurg 102:673-677, 2005

27. Maruyama K, Kamada K, Shin M, Itoh D, Masutani Y, Ino $\mathrm{K}$, et al: Optic radiation tractography integrated into simulated treatment planning for Gamma Knife surgery. J Neurosurg 107:721-726, 2007

28. Maruyama K, Kawahara N, Shin M, Tago M, Kishimoto J, Kurita H, et al: The risk of hemorrhage after radiosurgery for cerebral arteriovenous malformations. N Engl J Med 352: 146-153, 2005

29. Meyer-Heim AD, Boltshauser E: Spontaneous intracranial haemorrhage in children: aetiology, presentation and outcome. Brain Dev 25:416-421, 2003

30. Mohr JP, Parides MK, Stapf C, Moquete E, Moy CS, Overbey JR, et al: Medical management with or without interventional therapy for unruptured brain arteriovenous malformations (ARUBA): a multicentre, non-blinded, randomised trial. Lancet 383:614-621, 2014

31. Nicolato A, Lupidi F, Sandri MF, Foroni R, Zampieri P, Mazza C, et al: Gamma Knife radiosurgery for cerebral arteriovenous malformations in children/adolescents and adults. Part II: Differences in obliteration rates, treatment-obliteration intervals, and prognostic factors. Int J Radiat Oncol Biol Phys 64:914-921, 2006

32. Nussbaum ES, Heros RC, Camarata PJ: Surgical treatment of intracranial arteriovenous malformations with an analysis of cost-effectiveness. Clin Neurosurg 42:348-369, 1995

33. Pan DH, Kuo YH, Guo WY, Chung WY, Wu HM, Liu KD, et al: Gamma Knife surgery for cerebral arteriovenous malformations in children: a 13 -year experience. J Neurosurg Pediatr 1:296-304, 2008

34. Pollock BE, Kondziolka D, Lunsford LD, Bissonette D, Flickinger JC: Repeat stereotactic radiosurgery of arteriovenous malformations: factors associated with incomplete obliteration. Neurosurgery 38:318-324, 1996

35. Sharma MS, Kondziolka D, Khan A, Kano H, Niranjan A, Flickinger JC, et al: Radiation tolerance limits of the brainstem. Neurosurgery 63:728-733, 2008

36. Shin M, Kawahara N, Maruyama K, Tago M, Ueki K, Kirino T: Risk of hemorrhage from an arteriovenous malformation confirmed to have been obliterated on angiography after stereotactic radiosurgery. J Neurosurg 102:842-846, 2005 
37. Shin M, Kawamoto S, Kurita H, Tago M, Sasaki T, Morita A, et al: Retrospective analysis of a 10-year experience of stereotactic radio surgery for arteriovenous malformations in children and adolescents. J Neurosurg 97:779-784, 2002

38. Shin M, Maruyama K, Kurita H, Kawamoto S, Tago M, Terahara A, et al: Analysis of nidus obliteration rates after gamma knife surgery for arteriovenous malformations based on long-term follow-up data: the University of Tokyo experience. J Neurosurg 101:18-24, 2004

39. Smyth MD, Sneed PK, Ciricillo SF, Edwards MS, Wara WM, Larson DA, et al: Stereotactic radiosurgery for pediatric intracranial arteriovenous malformations: the University of California at San Francisco experience. J Neurosurg 97:4855,2002

40. Spetzler RF, Martin NA: A proposed grading system for arteriovenous malformations. J Neurosurg 65:476-483, 1986

41. Stapf C, Khaw AV, Sciacca RR, Hofmeister C, Schumacher HC, Pile-Spellman J, et al: Effect of age on clinical and morphological characteristics in patients with brain arteriovenous malformation. Stroke 34:2664-2669, 2003

42. Stapf C, Mast H, Sciacca RR, Choi JH, Khaw AV, Connolly ES, et al: Predictors of hemorrhage in patients with untreated brain arteriovenous malformation. Neurology 66:1350-1355, 2006

43. Steinberg GK, Chang SD, Levy RP, Marks MP, Frankel K, Marcellus M: Surgical resection of large incompletely treated intracranial arteriovenous malformations following stereotactic radiosurgery. J Neurosurg 84:920-928, 1996

44. Tamura N, Hayashi M, Chernov M, Tamura M, Horiba A, Konishi Y, et al: Outcome after Gamma Knife surgery for intracranial arteriovenous malformations in children. J Neurosurg 117 Suppl:150-157, 2012
45. Wegner RE, Oysul K, Pollock BE, Sirin S, Kondziolka D, Niranjan A, et al: A modified radiosurgery-based arteriovenous malformation grading scale and its correlation with outcomes. Int J Radiat Oncol Biol Phys 79:1147-1150, 2011

46. Yamada S, Takagi Y, Nozaki K, Kikuta K, Hashimoto N: Risk factors for subsequent hemorrhage in patients with cerebral arteriovenous malformations. J Neurosurg 107:965972, 2007

47. Yen CP, Monteith SJ, Nguyen JH, Rainey J, Schlesinger DJ, Sheehan JP: Gamma Knife surgery for arteriovenous malformations in children. J Neurosurg Pediatr 6:426-434, 2010

48. Yoshida K, Ichikawa T, Kurozumi K, Yanai H, Onoda K, Date I: Fatal glioblastoma after Gamma Knife radiosurgery for arteriovenous malformation in a child. J Clin Neurosci 21:1453-1455, 2014

\section{Author Contributions}

Conception and design: all authors. Acquisition of data: Hanakita, Koga. Analysis and interpretation of data: Hanakita, Koga. Drafting the article: Hanakita, Koga, Shin, Saito. Critically revising the article: Koga, Shin, Igaki, Saito. Reviewed submitted version of manuscript: all authors. Approved the final version of the manuscript on behalf of all authors: Hanakita. Study supervision: Koga, Igaki, Saito.

\section{Correspondence}

Shunya Hanakita, Department of Neurosurgery, The University of Tokyo Hospital, 7-3-1 Hongo, Bunkyo-ku, Tokyo 113-8655, Japan.email: hanakita-s@umin.ac.jp. 